\title{
Rancang Bangun Purwarupa Aplikasi Deteksi Dini Penyakit Jantung Berbasis Case Base Reasoning dengan Keamanan Data
}

\author{
Nur Afny C. Andryani ${ }^{1}$, Muhamad Femy Mulya ${ }^{2}$, Surnanto, M. Rizam Kusfandi ${ }^{3}$ \\ ${ }^{1,2,3}$ Informatics Engineering \& Information System, Tanri Abeng University \\ 'nur.afny@tau.ac.id
}

Diterima : 31 Agustus 2021

Disetujui : 28 September 2021

\begin{abstract}
The prevalence of heart disease has been consistently increasing in five recent years. In average 15 out of 1000 people have heart disease. Currently heart disease becomes the second leading cause of death in Indonesia. Early detection will guide the appropriate treatments to increase recovery opportunity. In another hand, many healthcare facilities in Indonesia are not equipped with the cardiologist. It triggers many heart disease cases are late to handle due late detection. Thus, we propose web based early heart disease detection application prototype using Case Base Reasoning framework. It is intended to support small clinic or other healthcare facilities which have no cardiologist to provide early detection of heart disease. The application is equipped with data security to handle the data privacy of the patient. Based on the black box evaluation by the expert, it is concluded that all the provided features can be run functionally.
\end{abstract}

\section{Keywords: Case Base Reasoning, Deteksi Dini Penyakit Jantung}

\section{PENDAHULUAN}

Angka kejadian penyakit jantung menunjukkan peningkatan dari tahun ke tahun [1]. Statistik menunjukkan 15 dari 1000 orang terjangkit penyakit jantung [1]. Penyakit ini juga merupakan penyebab kematian tertinggi kedua di Indonesia. Seringkali penyakit jantung terlambat dideteksi sehingga penanganannya seringkali sudah terlambat dan menyebabkan resiko kematian yang lebih tinggi.

Tenaga ahli jantung atau yang sering dikenal dengan Dokter Spesialis Jantung masih sangat terbatas dan belum tersebar secara merata di fasilitas kesehatan yang ada di Indonesia. Padahal deteksi dini akan sangat membantu penanganan penyakit Jantung dengan lebih cepat dan tepat. Sehingga menurunkan angka resiko kematian akan penyakit ini.
Inovasi bidang rekayasa dan teknologi untuk mendukung kebutuhan pelayanan medis terus berkembang. Salah satunya adalah pembangunan Sistem komputasi cerdas yang dapat membantu tenaga Medis melalukan diagnose sebuah penyakit [2] [3] [4]. Dalam penelitian ini diusulkan Rancang Bangun purwarupa aplikasi berbasis Web yang ditujukan untuk melakukan identifikasi awal penyakit jantung. Mesin inferensi dibangun menggunakan metode Case Base Reasoning (CBR). Aplikasi yang dibangun dilengkapi dengan fitur keamanan data menggunakan $Q R$ code. Aplikasi yang dibangun ditujukan untuk dapat membantu fasilitas kesehatan yang belum memiliki tenaga ahli Dokter Spesialis Jantung untuk dapat memberikan pelayanan deteksi dini penyakit jantung. 


\section{TEORI PENDUKUNG}

\section{A. Case Base Reasoning (CBR)}

Beberapa sumber pustaka menyebutkan bahwa CBR merupakan pengembangan dari Kerangka Sistem Pakar. CBR menggunakan pengetahuan di masa lampau untuk membentuk model inferensi. Basis pengetahuan yang dibangun merupakan bentuk beberapa kasus lampau dimana merupakan data berpasangan antara masalah dan jawabannya [2] [5] [6]. Hasil kesimpulan inferensi diputuskan berdasarkan skor indek similiarity yang merupakan bagian dari algoritma CBR. Persamaan index similiarity dijelaskan dalam persamaan (1) pada perancangan CBR.

\section{B. Deteksi Dini Penyakit Jantung}

Deteksi Dini penyakit jantung pada penelitian ini adalah deteksi awal adanya penyakit jantung yang ditandai dengan gejala khas. Dikatakan dini dikarenakan purwarupa aplikasi deteksi jantung yang diusulkan ditujukan untuk melakukan skrining awal adanya potensi penyakit jantung berdasarkan beberapa gejala khas. Rujukan menjadi salah satu fitur dalam purwarupa aplikasi yang diusulkan untuk telaah kasus yang lebih serius.

\section{PERANCANGAN APLIKASI}

Pada bagian ini akan dipaparkan Tahapan pembangunan purwarupa aplikasi serta desain aplikasi yang dilakukan sebelum proses pembangunan aplikasi. Dalam pembangunan aplikasi deteksi dini penyakit jantung ini, dilakukan rancangan tahapan pembangunan aplikasi yang dibangun menggunakan metode Scrum [7] serta pembangunan desain aplikasi dengan metode UML. Pada bagian ini juga akan dijelaskan perancangan Case Base Reasoning yang merupakan mesin inferensi pada aplikasi deteksi dini penyakit jantung yang diusulkan.

\section{A. Tahapan pembangunan aplikasi dengan Scrum}

Berikut adalah tahapan pembangunan aplikasi Deteksi dini penyakit jantung menggunakan metode Scrum

\section{A.1 Product Backlog}

Melakukan pengumpulan kebutuhan sistem perangkat lunak, kebutuhan sistem ditentukan mengikuti analisa dan observasi yang dilakukan sebelumnya. Setelah kebututhan perangkat lunak dikumpulkan dan dibuat product backlog, maka akan di urutkan berdasarkan urutan prioritas untuk nantinya dicacah di dalam sprint.

\section{A.2 Sprint Backlog}

Perencanaan Sprint dilakukan dalam pertemuan / meeting antara pihak klinik dan kami penulis sebagai developer aplikasi, yang akan berkolaborasi untuk memilih product backlog untuk dimasukkan kedalam proses Sprint. Hasil dari pertemuan tersebut adalah Sprint Backlog.

\section{A.3 Sprint}

Dalam Scrum, Sprint adalah sebuah kerangka waktu yang berdurasi maksimal 1 bulan untuk mengembangkan produk yang berpotensi untuk dirilis. Dalam Sprint terdapat 2 bagian pekerjaan, yaitu:

1. Pertemuan Harian merupakan pertemuan dimana setiap 24 jam (1 hari), kami bertemu untuk membahas proses pengembangan produk dalam hal ini yaitu pembuatan pembangunan aplikasi deteksi dini penyakit jantung.

2. Refleksi merupakan pertemuan yang dilakukan setiap bulannya, yang bertujuan untuk membahas hal dari Sprint Backlog yang telah berjalan dan telah berhasil dikerjakan, serta dapat memperbaiki dan meningkatkan kualitas produk pada Sprint yang berikutnya.

\section{A.4 Increment}

Increment merupakan hasil dari seluruh hal dalam Product Backlog yang telah selesai dikerjakan pada seluruh Sprint. Pada akhir Sprint, Increment harus sudah benar-benar selesai, yang berarti harus dalam keadaan yang useable sesuai kebutuhan dari klink tersebut.

\section{B. Desian Aplikasi}

Dalam sub bab ini digambarkan desain aplikasi yang dibangun menggunakan metode UML 


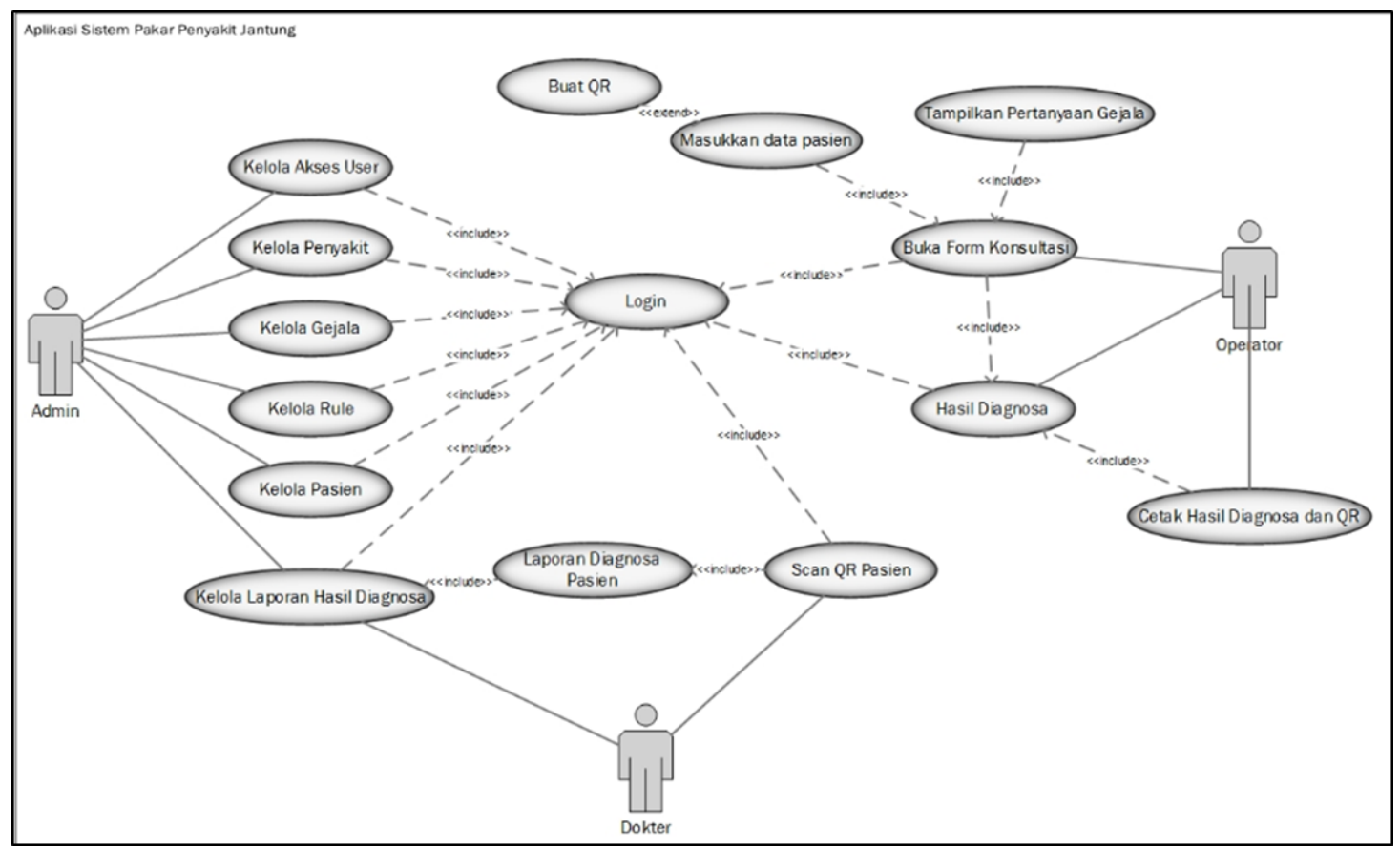

Gambar 1. Use case diagram Aplikasi Deteksi Dini Penyakit Jantung berbasis CBR

Pada Gambar 1 diatas dijelaskan desain aplikasi deteksi dini penyakit jantung berbasis CBR yang diusulkan. Dalam diagram tersebut dapat digambarkan bahwa terdapat 3(tiga) aktor utama dalam aplikasi yang diusulkan. Tiga aktor tersebut adalah dokter atau tenaga medis, operator klinik atau layanan fasilitas kesehatan dan admin pengelola aplikasi. Alur proses dari aplikasi deteksi dini penyakit jantung berbasis CBR yang diusulkan ditampilkan dalam diagram activity yang dijelaskan dalam Gambar 2. Berikut. Aplikasi deteksi jantung yang dibangun dilengkapi dengan kemanan data dengan $Q R$ code [8].

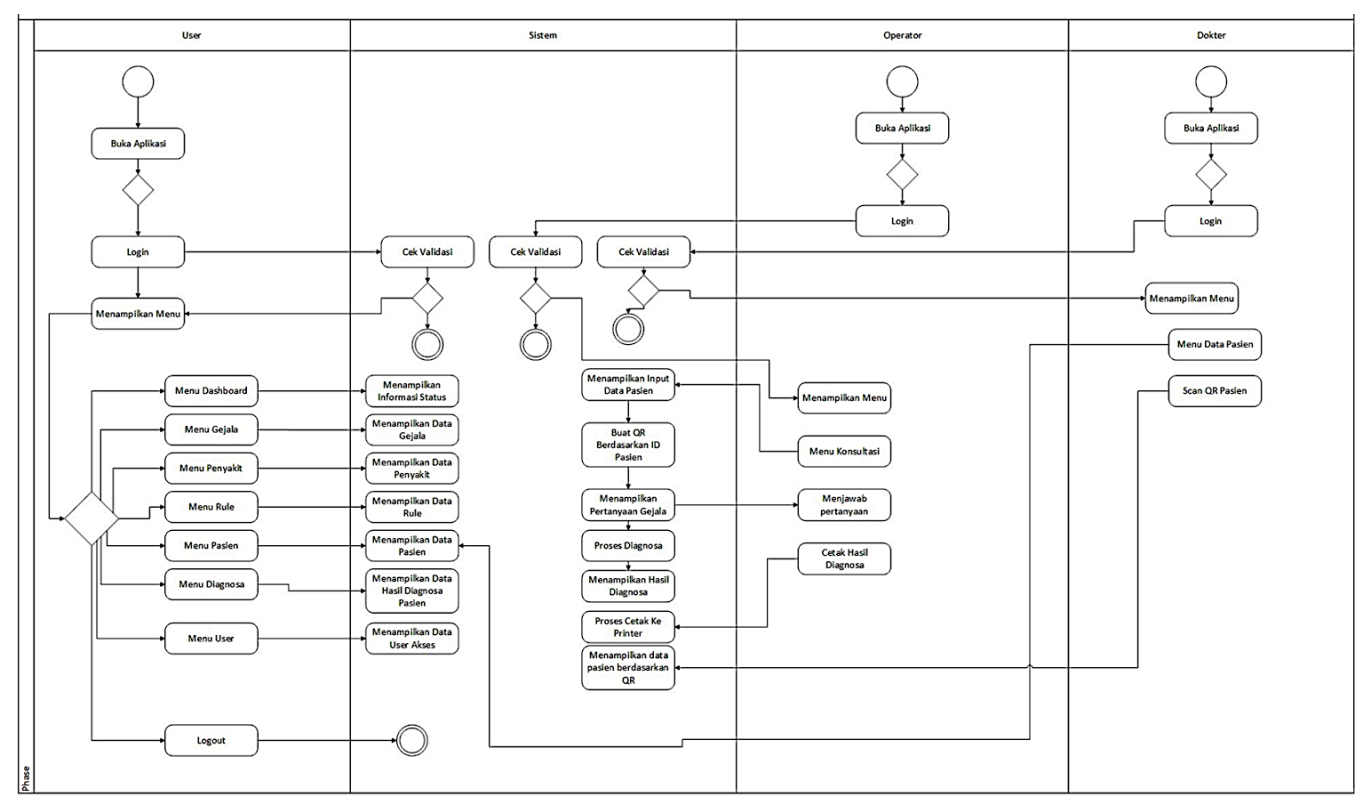

Gambar 2. Diaram Activity untuk Aktor Tenaga Medis (Dokter), Operator dan Admin 


\section{Perancangan Case Base Reasoning (CBR)}

Seperti yang telah disebutkan sebelumnya bahwa aplikasi yang dibangun menggunakan mesin inferensi berbasis CBR. Maka perlu dibangun rancangan CBR yang diperuntukkan bagi aplikasi deteksi dini penyakit jantung yang diusulkan. Dalam Tabel 1 sampai dengan Tabel 3 dijelaskan rancangan CBR untuk aplikasi yang diusukan. Rancangan tersebut terdiri atas data basis pengetahuan jenis penyakit jantung, data basis pengetahuan gejala penyakit, serta data basis relasi antara penyakit dan gejala yang telah diberikan bobot. Pengetahuan terkait penyakit jantung, gejala serta pemeberian bobot adalah berdasarkan konsultasi dengan dr. Edward Syam MKes selaku tenaga medis dokter di Klinik Pesona Medika tempat dilakukannya penelitian. Informasi dari dokter tersebut berdasarkan dokumen tata laksana penyakit kardiovaskuler bagi dokter.

Tabe 1. Data Penyakit Jantung

\begin{tabular}{|c|c|}
\hline kode & penyakit \\
\hline P001 & Gagal Jantung \\
\hline P002 & Heart Valve Disease \\
\hline P003 & Aritmia \\
\hline P004 & Perikarditis \\
\hline P005 & $\begin{array}{c}\text { Penyakit Jantung } \\
\text { Koroner }\end{array}$ \\
\hline
\end{tabular}

Tabel 1 menampilkan data jenis penyakit yang dimungkinkan diidentifikasi dengan aplikasi yang dibangun, Tabel 2 merangkum gejala gejala yang menjadi pertanda khas penyakit jantung tertentu, sedangkan Tabel 3 adalah Tabel basis pengetahuan yang merelasikan antara gejala dengan penyakit jantung terkait. Relasi ini didasarkan pada anotasi bobot oleh tenaga medis (dokte klinik tempat penelitian).

Tabel 2. Data Gejala Khas Penyakit Jantung

\begin{tabular}{|c|c|}
\hline Kode & Gejala \\
\hline G001 & Dada terasa penuh \\
\hline G002 & Detak jantung cepat (tachycardia) \\
\hline G003 & Detak jantung lambat (bradycardia) \\
\hline G004 & Nyeri pada dada \\
\hline G005 & Panas \\
\hline G006 & baik napas \\
\hline G007 & $\begin{array}{c}\text { katup jantung tidak bekerja dengan } \\
\text { bunyi jantung abnormal }\end{array}$ \\
\hline G008 & kebocoran, penyempitan \\
\hline G009 & Badan lesu atau lemah \\
\hline G010 & Pusing \\
\hline G011 & $\begin{array}{c}\text { Pingsan (syncope) } \\
\text { G014 tidur karena gangguan rasa }\end{array}$ \\
\hline G012 & $\begin{array}{c}\text { katup jantung tanpa lubang } \\
\text { G013 }\end{array}$ \\
\hline G015 & denyut nadi yang lemah dan cepat \\
\hline
\end{tabular}

Table 3. Basis Pengetahuan Relasi Gejala dan Penyakit serta Nilai Bobot

Berdasarkan Basis Pengetahuan Pakar (Sumber, Dokter Klinik Tempat Penelitian

\begin{tabular}{|c|c|r|r|r|}
\hline \multicolumn{2}{|c|}{ Gejala } & \multicolumn{2}{c|}{ Penyakit } \\
\cline { 1 - 3 } Kode & Gejala & Bobot & Kode & Penyakit \\
\cline { 1 - 3 } G015 & denyut nadi yang lemah dan cepat & 1 & & \\
\cline { 1 - 3 } G011 & Pusing & 0.6 & P001 & Gagal Jantung \\
\cline { 1 - 3 } G008 & bunyi jantung abnormal & 0.8 & & \\
\hline
\end{tabular}




\begin{tabular}{|c|c|c|c|c|}
\hline G013 & katup jantung tanpa lubang & 1 & \multirow{3}{*}{ P002 } & \multirow{3}{*}{ Heart Valve Disease } \\
\hline G009 & kebocoran, penyempitan & 0.8 & & \\
\hline G007 & katup jantung tidak bekerja dengan baik & 1 & & \\
\hline G012 & Pingsan (syncope) & 1 & \multirow{7}{*}{ P003 } & \multirow{7}{*}{ Aritmia } \\
\hline G011 & Pusing & 0.6 & & \\
\hline G006 & Sesak napas & 0.4 & & \\
\hline G004 & Nyeri pada dada & 1 & & \\
\hline G003 & Detak jantung lambat (bradycardia) & 1 & & \\
\hline G002 & Detak jantung cepat (tachycardia) & 0.4 & & \\
\hline G001 & Dada terasa penuh & 0.4 & & \\
\hline G008 & bunyi jantung abnormal & 0.4 & \multirow{3}{*}{ P004 } & \multirow{3}{*}{ Perikarditis } \\
\hline G006 & Sesak napas & 1 & & \\
\hline G005 & Panas & 0.4 & & \\
\hline G013 & Pusing & 0.4 & \multirow{2}{*}{ P005 } & \multirow{2}{*}{$\begin{array}{l}\text { Penyakit Jantung } \\
\text { Koroner }\end{array}$} \\
\hline G011 & Badan lesu atau lemah & 0.4 & & \\
\hline
\end{tabular}

Berdasarkan beberapa informasi pada ketiga tabel diatas maka penentuat identifikasi penyakit dintentukan dengan nilai index similiaritas antara data yang ditemui dilapangan dengan model yang telah dibentuk berdasarkan nilai bobot dari pakar. Berikut adalah rumusan yang digunakan untuk menentukan bobot similaritas [5] [4]

$$
\begin{aligned}
& \text { Similarity } \\
& =\frac{S 1 \times W 1+S 2 \times W 2+\cdots+S n \times W n}{W 1+W 2+\cdots+W n}
\end{aligned}
$$

dimana,

$\mathrm{S}=$ similarity (nilai kemiripan) yaitu 1 (sama) dan 0 (beda)

$\mathrm{W}=$ weight (bobot yang diberikan seperti halnya disampaikan dalam Tabel 3).

Berdasarkan perhitungan index similarity dalam persamaan (1) diatas yang digunakan untuk menjadi dasar dalam memberikan hasil diagnose penyakit jantung berdasarkan nilai input user.

\section{PEMBANGUNAN APLIKASI}

Tahapan pembangunan aplikasi adalah bagaimana mentransformasi desain baik desain sistem maupun sistem inferensi kedalam bentuk aplikasi yang bisa diakses dengan mudah oleh pengguna. Pembangunan aplikasi dekstop sistem deteksi penyakit jantung ini dibangun dengan bahasa pemograman Java dan $\underline{P H P}$. Sedangkan pembangunan basis data dilakukan dengan menggunakan MySQL.

Pada bagian ini disampaikan tampilan serta fungsi aplikasi yang dibangun. Dalam Gambar 3 Gambar 8 disampaikan langkah langkah penggunaan aplikasi dalam membangun diagnosa awal penyakit jantung. Menu yang ditampilkan adalah menu yang dapat diakses oleh operator klinik (dokter umum) untuk membantu menduku ng diagnose awal dokter umum sebelum nantinya ditentukan perlu dirujuk kepada dokter jantung atau tidak. 


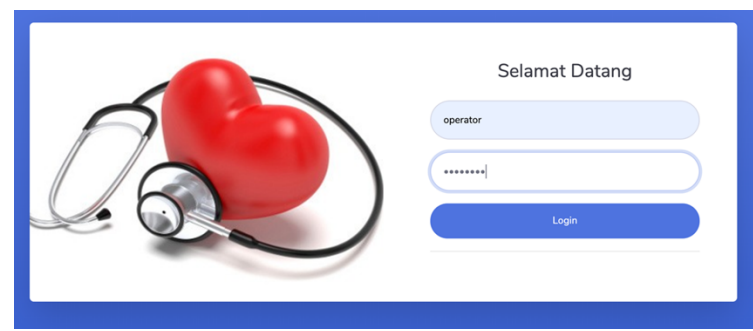

Gambar 3. Menu Login Aplikasi

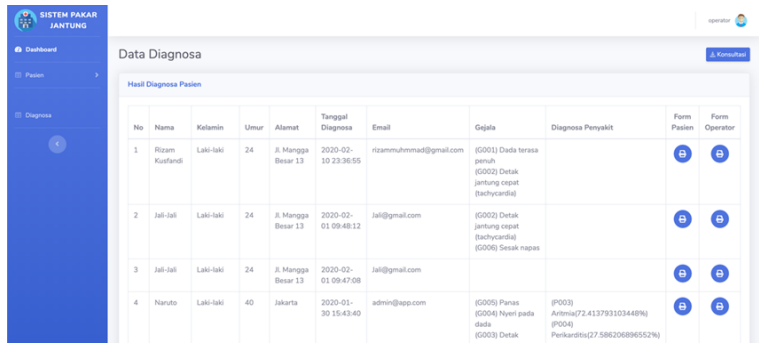

Gambar 5. Menu Utama Operator Untuk Seluruh data Pasien yang hendak Dilakukan diagnosa

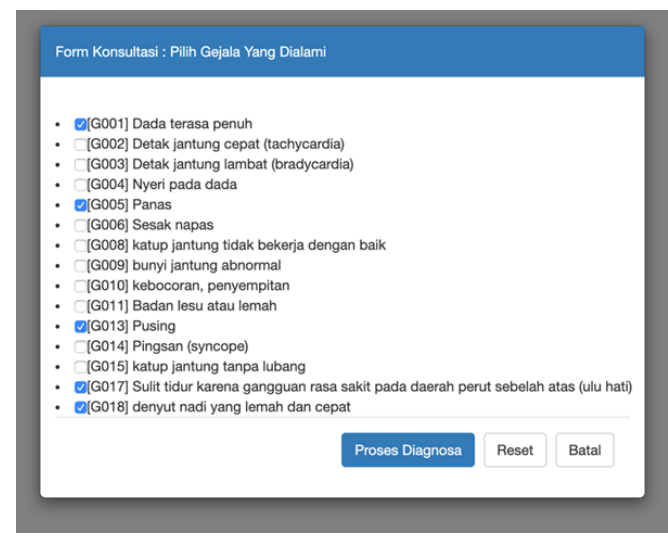

Gambar 7. Menu Pemindai Gejala

\section{Pengujian Purwarupa APLiKasi}

Pada bagian ini akan dibahas secara singkat pengujian Purwarupa Aplikasi deteksi jantung yang diusulkan. Dalam Pengujian purwarupa ini digunakan metode Black box dengan melibatkan tenaga medis (dokter umum) klinik tempat penelitian untuk melakukan pengujian fungsi
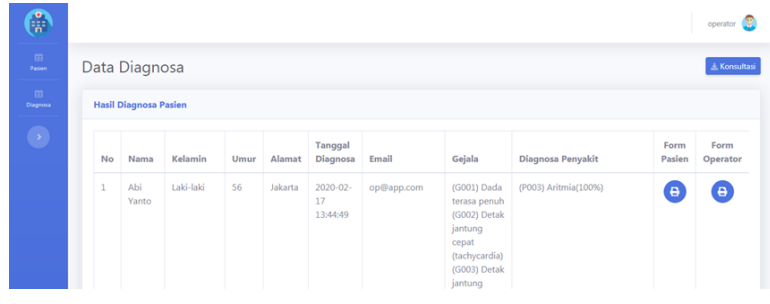

Gambar 4. Menu Utama Operator Data Pasien

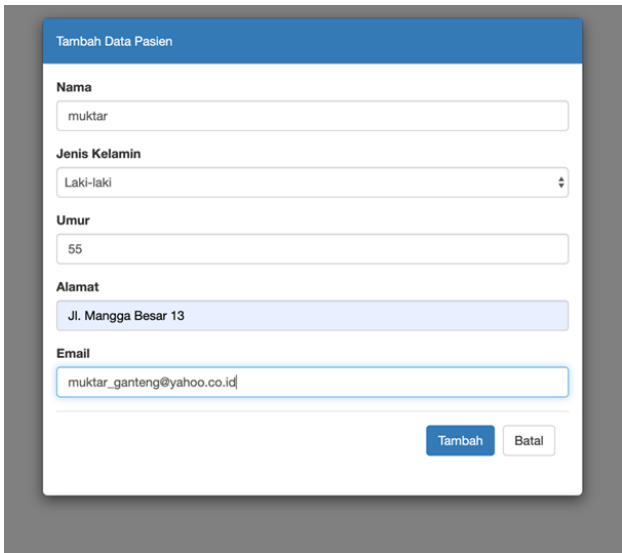

Gambar 6. Tambah Data Pasien untuk proses Diagnosa

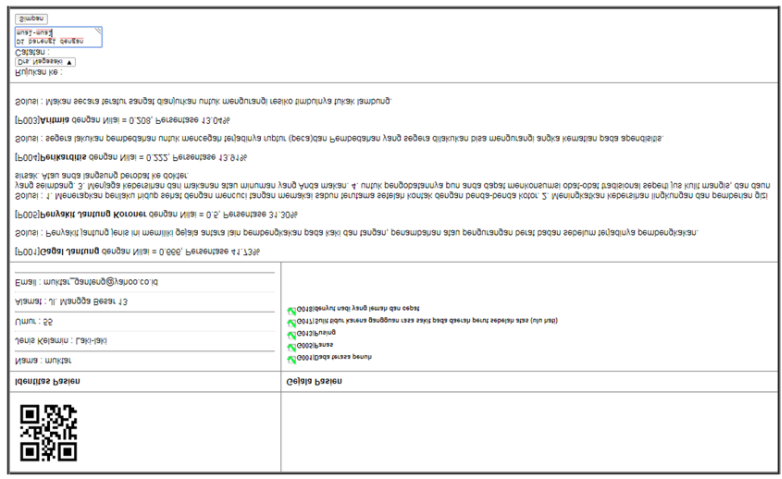

Gambar 8. Tampilan Output disertai QR Code untuk keamanan data Pasien

sebegaimana yang tertera dalam Tabel 4 berikut ini. Berdasarkan keterangan dalam Tabel 4 dapat disimpulkan bahwa Purwarupa aplikasi deteksi penyakit jantung yang diusulkan secara fungsi, seluruh fiturnya telah dapat divalidasi 
Tabel 4. Pengujian Purwarupa menggunakan Metode Black Box

\begin{tabular}{|c|c|c|c|c|c|c|}
\hline No & Kelas Uji & Daftar Pengujian & Kasus Uji & $\begin{array}{l}\text { Hasil yang } \\
\text { diharapkan }\end{array}$ & $\begin{array}{l}\text { Valid }(\checkmark) \text { atau } \\
\text { Tidak Valid (x) }\end{array}$ & Penguji \\
\hline 1. & $\begin{array}{l}\text { Fungsi pada } \\
\text { Menu } \\
\text { Pasien }\end{array}$ & $\begin{array}{l}\text { Pengujian } \\
\text { Melakukan Scan } \\
\text { QR Code }\end{array}$ & $\begin{array}{l}\text { Dokter melakukan } \\
\text { klik menu Scan } \\
\text { QR, kemudian QR } \\
\text { Code yang tertera } \\
\text { pada kertas yang } \\
\text { dipegang oleh } \\
\text { pasien diarahkan } \\
\text { ke kamera }\end{array}$ & $\begin{array}{l}\text { Jika data } \\
\text { sesuai rujukan } \\
\text { maka data } \\
\text { pasien akan } \\
\text { ditampilkan, } \\
\text { jika rujukan } \\
\text { tidak sesuai } \\
\text { maka data } \\
\text { dikosongkan }\end{array}$ & $\checkmark$ & $\begin{array}{l}\text { Bapak Femy } \\
\text { Dr. Edu }\end{array}$ \\
\hline 2. & $\begin{array}{l}\text { Fungsi pada } \\
\text { Menu } \\
\text { Diagnosa }\end{array}$ & $\begin{array}{l}\text { Pengujian } \\
\text { menampilkan } \\
\text { halaman data } \\
\text { pasien yang sudah } \\
\text { melakukan } \\
\text { konsultasi } \\
\text { berdasarkan } \\
\text { rujukan }\end{array}$ & $\begin{array}{l}\text { Dokter memilih } \\
\text { menu Diagnosa }\end{array}$ & $\begin{array}{l}\text { Data yang } \\
\text { ditampilkan } \\
\text { hanya data } \\
\text { berdasarkan } \\
\text { rujukan yang } \\
\text { dirujuk ke } \\
\text { dokter } \\
\text { tersebut }\end{array}$ & $\checkmark$ & $\begin{array}{c}\text { Bapak Femy } \\
\text { Dr. Edu }\end{array}$ \\
\hline
\end{tabular}

\section{SIMPULAN}

Telah dibangun purwarupa aplikasi deteksi penyakit jantung berbasis web yang dilengkapi dengan keamanan data. Sistem inferensi yang digunakan untuk melakukan deteksi penyakit jantung dibangun dengan menggunakan Algoritma CBR. Purwarupa ini ditujukan untuk nantinya mampu membantu fasilitas kesehatan yang belum memiliki dokter spesialis jantung untuk dapat melakukan diagnose awal penyakit jantung bagi pasien.

Purwarupa aplikasi deteksi jantung berbasis web ini juga dilengkapi fitur keamanan data berbasis QR code. Fitur ini ditujukan untuk menjaga kerahasiaan data pasien sehingga hanya pihak tertentu yang berhak membaca hasil diagnosa.

Dalam pembangunan purwarupa aplikasi deteksi penyakit jantung ini menggunakan metode Scrum. Sedangkan pengujian validitas performa purwarupa aplikasi menggunakan metode Black Box. Dari hasil pengujian yang dilakukan oleh dokter klinik didapatkan hasil seluruh fungsi pada purwarupa aplikasi berjalan dengan sesuai. Purwarupa aplikasi deteksi jantung mampu membantu memberikan gambaran awal diagnose penyakit jantung bagi petugas medis umum. Namun demikian penegakan diagnosa utamanya untuk kasus berat tetap memerlukan keahlian analisa lebih lanjut dari dokter Spesialis Jantung. Dalam Purwarupa aplikasi yang dibangun, hal ini diakomodasi dengan memberikan fitur rujukan pada aplikasi.

Untuk menentukan kelayakan penggunaan aplikasi yang dibangun, maka dilakukan pengujian black box untuk memastikan seluruh fitur yang disediakan dan difungsikan sebagaiamana mestinya. Pengujian dilakukan oleh sumber ahli medis (dokter klinik) dan sumber ahli software Engineering. Berdasarkan hasil pengujian dapat ditunjukkan bahwa seluruh fitur yang dibangun dapat difungsikan dengan baik. Hasil inferensi juga telah sesuai dengan pengetahuan tenaga ahli medis. Proses keamanan data juga sudah tervalidasi. Sehingga dapat dikatakan fungsi utama dari aplikasi yang diusulkan sudah dapat divalidasi. 


\section{DAFTAR PUSTAKA}

[1] H. Hafizhah, "Republika," 14 June 2021. [Online]. Available: https://www.republika.co.id/berita/qunz0f428/menko-pmk-15dari-1000-orang-menderita-penyakit-jantung.

[2] S. H. Tedy Rismawan, "Case-Based Reasoning untuk Diagnosa Penyakit THT," Indonesian Journal of Computing and Cybernetics Systems, vol. 6, no. 2, pp. 67-78, 2012.

[8] D. Prabowo, "Rancangan Bangun Aplikasi Historical

[3] e. a. Jessica Velasco., "A Smartphone-Based Skin Disease Classification Using MobileNet CNN," International Journal of Advanced Trends in Computer Science and Engineering, vol. 8, no. 5, pp. 2633-2637, 2019.

[4] D. R. K. a. P. T. D. R. C P C Munaiseche, "An Expert System for Diagnosing Eye Diseases using Forward Chaining Method," in IOP Publisher, 2017.

[5] S. K. Z. a. S. Vasupongayya, "A Case-Based Reasoning Approach for Automatic Adaptation of Classifier in Mobile Phising Detection," Journal of Computer Networks and Communications, vol. 2019, p. 14, 2019.
[6] H. C. ,. B. G. Z. T. a. X. L. Jianping Sun, "Demand Prediction of Railway Emergency Resources Based on Case-Based Reasoning," Journal of Advance Transportation, vol. 2021, pp.

"http://www.agilemodeling.com/," Agile Modelling, [Online]. Available:

http://www.agilemodeling.com/essays/introductionToAM.htm. [Accessed 28 May 2021].

Maintance Kendaraan Bus Menggunakan Teknologi QR code Berbasis Android," Skripsi Program Studi Teknik Informatika UIN Jakarta, 2014. 1-9, 2021. 